\title{
Agave spins and Gingko Biloba leaves to exorcise the passage from BCC to real skin melanoma during time
}

\section{Lorenzo Martini1 ${ }^{1,2}$, Francesco D'Agostino³, Piotr Brzeziński ${ }^{4}$}

\author{
${ }^{1}$ University of Siena, Department of Pharmaceutical Biotechnologies, Via A. Moro 2, 53100 Siena, Italy, ${ }^{2}$ C.R.I.S.M.A. Inter \\ University Centre for Researched Advanced Medical Systems, Via A. Moro 2, 53100 Siena, Italy, ${ }^{3}$ Acquafrescaio, Terra dei \\ Fuochi, Neaples, Italy, ${ }^{4}$ Department of Physiotherapy and Medical Emergency, Faculty of Health Sciences, Pomeranian \\ Academy, Slupsk, Poland
}

Corresponding author: Prof. Lorenzo Martini, M.Sc, E-mail: lorenzo.martini@unisi.it

\section{INTRODUCTION}

Discharges of radioactive scoria are hidden in manifold provinces and lands throughout all Europe and too often they are interred underneath several euphemistic "Natural Parks".

These are the chief centers of pituital Death in Europe:

Olkiuoto (SF); Lovisa (SF); Tammiku (Est); Baldone (LV); Ignalina (LT); Maisiagala (LT); Morsleben (D); Rozan (PL); Konrad (D); Asse (D); Richard (CZ); Hostim (CZ); Dukovany (CZ); Mahovce (SK); Puspokzilagy (H); Baita Bihor (RO); Bataapati $(\mathrm{H})$; Saligny (RO); Brinje (SL); Radiana (BG); Vbina (SL); Novi Han (BG); Kjeller (N); Himdalen (N); Forsmark (S); Drigg (UK); Borseele (NL); Dessel (B); La Manche (F); LAube (F); Bratrstvi (CZ); El Cabril (E).

Many of them are in operation, many of them are closed but can emit radioactivity or evoke decay of radioactive metals and many of them are under construction.

In Italy, first of all, the notorious Capria, a simplest agricultural park at Capriano del Colle in Lombardy, hides more than 82500 tons of scoria of Cesium 137, and moreover one can number other 4 nuclear plants in decommissioning (Sogin); 4 systems for the cycle of combustible in decommissioning (Enea/ Sogin); 1 reactor of research CCR ISPRA-1 (Sogin); 7 centres for research for nuclear activity (ENEA Casaccia, CCR Ispra, Deposito Avogadro, LivaNova, CESNEF -Centro Energia e Studi Nucleari Enrico
Fermi- University of Pavia, University of Palermo); 3 centres of Integrated Services that are fully working (Nucleco, Campoverde, Protex); l center of Integrated Service no more active yet. (Cemerad).

These are in the provinces of Vicenza, Alessandria, Milano, Varese, Pisa, Forlì, Roma, Latina, Taranto, Matera, Caserta, Palermo and recently (2019) radon from subsoil have been detected in Bisenzio, Lastra a Signa, Scandicci, Sesto Fiorentino and Signa, close to Florence.

The awful disaster of Chernobyl (1986) delivered a $3.5 \%$ of perilous radioactivity (50\% of Cesium 134-137, $60 \%$ of Iodine 131, and Krtipton and Xenon (gazes) on account of $100 \%$.

Some Researchers [1] in 2014 noticed that mices irradiated by radioactive agents showed drastic disfunctions at niveau of their skin and tried to find a special natural lotion to spread upon animals's hair in order to treat or prevent some undesirable consequences due to radioactivity and/or decay of radioactive metals, as Cesium or Iodine isotopes. The first step of ionizing radiation on skin is the basal cell carcinoma.

Basal cell carcinoma (BCC) is the most common form of skin cancer and the most frequently occurring form of all cancers [2].

Because BCCs grow slowly, most are curable and cause minimal damage when caught and treated early. Understanding BCC causes, risk factors and warning

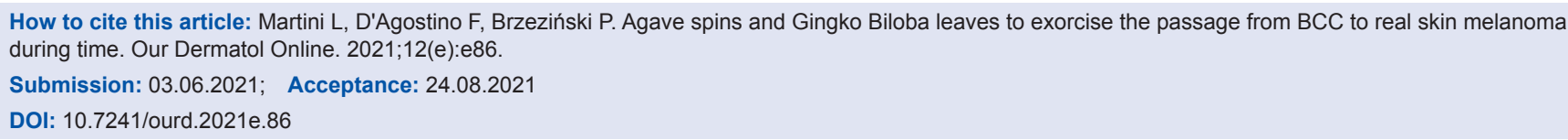


signs can help you detect them early, when they are easiest to treat and cure [3].

BCCs can look like open sores, red patches, pink growths, shiny bumps, scars or growths with slightly elevated, rolled edges and/or a central indentation. At times, BCCs may ooze, crust, itch or bleed. The lesions commonly arise in sun-exposed areas of the body. In patients with darker skin, about half of BCCs are pigmented (meaning brown in color) $[3,4]$.

So, it is really important to recognize the BCC before it becomes malignant and histological examinations are always useful.

The malignant skin cancer may occur following ionizing radiation exposure following a latent period averaging 20 to 40 years $[5,6]$. A chronic radiation keratosis is a precancerous keratotic skin lesion that may arise on the skin many years after exposure to ionizing radiation [7]. Various malignancies may develop, most frequency basal-cell carcinoma followed by squamous-cell carcinoma [2,8]. Elevated risk is confined to the site of radiation exposure [9]. Several studies have also suggested the possibility of a causal relationship between melanoma and ionizing radiation exposure [10].

The degree of carcinogenic risk arising from low levels of exposure is more contentious, but the available evidence points to an increased risk that is approximately proportional to the dose received [11]. Radiologists and radiographers are among the earliest occupational groups exposed to radiation. It was the observation of the earliest radiologists that led to the recognition of radiation-induced skin cancer-the first solid cancer linked to radiation-in 1902 [12,13]. While the incidence of skin cancer secondary to medical ionizing radiation was higher in the past, there is also some evidence that risks of certain cancers, notably skin cancer, may be increased among more recent medical radiation workers, and this may be related to specific or changing radiologic practices [12]. Available evidence indicates that the excess risk of skin cancer lasts for 45 years or more following irradiation.

The AA of this paper desired to follow this concern and try to study the effect of a similar lotion when spread onto people who are forced to live close the aforesaid centres of discharge od radioactive metals (especially in Terra del Fuoco at Caserta, Campania,Italy).
The oncologists of the aforesaid paper affirmed that Radiation-induced skin damage is one of the most common complications of radiotherapy. In order to combat these side effects, patients often turn to alternative therapies, which often include antioxidants. Antioxidants such as those in the polyphenol chemical class, xanthine derivatives, tocepherol, sucralfate, and ascorbate have been studied for their use in either preventing or treating radiotherapy-induced skin damage. Apart from their known role as free radical scavengers, some of these antioxidants appear to alter cytokine release affecting cutaneous and systemic changes. The oncologists reviewed the role of antioxidants in treating and preventing radiation-induced skin damage as well as the possible complications of using such therapy.

Some other Researchers [14] referred that most of ionizing radiations may evoke the main mechanism of radiation-induced effects that is is initiated through the production of reactive oxygen species (ROS). They designed the experience to determine the possible protective effects of Ginkgo biloba and Angelica archangelica against oxidative organ damage that was induced by radioactive 99 Technetium.

The extracts were administered parenterally, for sake of truth, but since the Superoxide-dismutase (SOD) that were measured in blood and lenses, is is primarly present in the epidermal layer. And this concern is well acquainted.

The AA of this article had prepared a glycolic lotion to spread onto the skins of people who live close the centers that provoke radioactive emissions (at Giugliano, Qualiano, Castelvolturno) that are the chief superscripts of the reality of the Terra dei Fuochi. (Campania).

The glycolic lotion contained aqueous extract of Gingko Biloba leaves and aqueous extract of Agave spp. spines.

The occurrence of tumors (thyroid, stomach, lungs and bones but even skin melanomas) in this land of Southern Italy is very huge and always increasing.

Manifold studies have been carried out explaining the efficacy of Gingko Biloba apt to minimize the occurrence of tumors. 
For example castogenic factors were found in the plasma of persons irradiated accidentally or therapeutically [15]. They persisted in the plasma of A-bomb survivors over 30 years. Clastogenic factors were found in 33 of 47 Chernobyl accident recovery workers (often referred to as liquidators) in a previous study (I. Emerit et al., J. Cancer Res. Clin. Oncol. 120, 558-561, 1994). The scientists referred that there is a positive correlation between clastogenic activity and dose and that these biomarkers of oxidative stress can be influenced successfully by appropriate antioxidant treatment. With the authorization of the Armenian Ministry of Health, 30 workers were treated with antioxidants from Ginkgo biloba leaves. The extract containing flavonoids and terpenoids was given at a daily dose of $3 \times 40 \mathrm{mg}$ during 2 months. The clastogenic activity of the plasma was reduced to control levels on the first day after the end of the treatment.

The antioxidant therapy to combat negative effects of radioactive metals regards to skin is supported by several analytical studies effectuated on the G.B. leaves.

For instance about 110 flavonoids have been reported to have unambiguous structures, including flavonol and its glycosides, flavone and its glycosides, flavanone and its glycosides, isoflavone and its glycosides, flavan-3-ols, bioflavonoids, and biginkgosides. In recent years, in addition to new flavonoids, new terpenoids and lignan have been also isolated from GBL [16].

Agave spp. spines are rich of polyphenols that elicit their antioxidant activity and moreover a very excellent skin barrier penetration.

Some researchers [17] focused their attention onto the spines exploring the chemical constituents of Agave fourcroydes (Mexico) and disclosed that metabolomic profiling based on accurate mass spectrometry reveal the presence of phenolic compounds including quercetin, kaempferol, (+)-catechin, and (-)-epicatechin.

It has been explored the capacity of polyphenols to penetrate the skin barrier and [17] determined that lipophilic phenols (instead of revealing a strong antioxidant activity) present the ability to penetrate deeper and more rapidly the skin barrier, and as far as the effectiveness is concerned epicatechin, resveratrol, quercetin are the best performing agents.

Agave spp. spines are rich of epicatechin and quercetin.

\section{MATERIALS AND METHODS}

The AA have recruited 12 volunteers who presented the first clear step of basal cell carcinoma.

No histological examination was carried out, but the dermatologist (the corresponding A) was capable to recognize the problem at its very beginning.

The lotion was made like this:

25\% Agave spins aqueous extract

25\% Gingko Biloba leaves aqueous extract

50\% Propylene Glycol.

The volunteers had to spread the lotion twice a day for one entire month, every morning and try to avoid sun exposure. (All the volunteers were employés or teachers or saylors etc.).

\section{RESULTS}

After one month the signs of the BCC disappeared in all the cases.

But right after the $8^{\text {th }}$ day it had been possible to observe a neat remission.

\section{CONCLUSIONS}

After the disaster of Chernobyl in 1986 many proximal trees died but many bushes and especially the longlived Gingko Biloba trees remained intact and alive in the surrounding of $12 \mathrm{~km}$ far from the explosion.

Since early 90 s creams based on G.B. leaves extract were prepared to whitening and softening skin, especially suffering from couperose.

\section{Statement of Human and Animal Rights}

All the procedures followed were in accordance with the ethical standards of the responsible committee on human experimentation (institutional and national) and with the 2008 revision of the Declaration of Helsinki of 1975.

\section{Statement of Informed Consent}

Informed consent for participation in this study was obtained from all patients. 


\section{REFERENCES}

1. Amber KT, Shiman MI, Badiavas EV. The use of antioxidants in radiotherapy-induced skin toxicity. Integr Cancer Ther. 2014;13:38-45.

2. Elloudi S, Oulehri A, Baybay H, Douhi Z, Mernissi FZ. Advanced basal cell carcinomas of the face: A Moroccan series. Our Dermatol Online. 2021;12:135-9.

3. Furukawa H, Sowa-Osako J, Ozawa T, Hashimoto T, Tsuruta D. A case of a long-neglected basal cell carcinoma on the scalp. Our Dermatol Online. 2021;12:206-7.

4. Mrabat S, Douhi Z, Elloudi S, Baybay H, Mernissi FZ. Pigmented plaque on the thigh: Atypical location of a basal cell carcinoma. Our Dermatol Online. 2021;12:195-6.

5. Henning A. Skin cancer and "Dr. YouTube." Using PEMAT Scoring to Determine Understandability and Actionability of Audiovisual Patient Education Material. Our Dermatol Online. 2020;11:309-11.

6. Laniauskaite L, Ožalinskaite A, Strupaite R, Bylaite M. Skin cancer knowledge, attitude and behavior towards sun exposure among young adults in Lithuania. Our Dermatol Online. 2011;2:189-5.

7. Oulehri A, Elloudi S, Baybay H, Douhi Z, Mernissi FZ. Vitiligo and skin cancer: what's the link? Our Dermatol Online. 2020;11:e144.1-e144.4.

8. Ait Ali H, Zeriouh B, Ebo Egyir U, Chablou M, Bouhout T, Serji B, Elharroudi T. Cutaneous squamous cell carcinoma (cSCC) arising from a chronic skin fi stula: A case report. Our Dermatol Online. 2021;12:280-4

9. Lichter MD, Karagas MR, Mott LA, Spencer SK, Stukel TA, Greenberg ER. Therapeutic ionizing radiation and the incidence of basal cell carcinoma and squamous cell carcinoma. The New Hampshire Skin Cancer Study Group. Arch Dermatol. 2000;136:1007-11.
10. Fink CA, Bates MN. Melanoma and ionizing radiation: is there a causal relationship? Radiat Res. 2005;164:701-10.

11. Wakeford R. The cancer epidemiology of radiation. Oncogene. 2004;23:6404-28.

12. Yoshinaga S, Mabuchi K, Sigurdson AJ, Doody MM, Ron E. Cancer risks among radiologists and radiologic technologists: review of epidemiologic studies. Radiology. 2004;233:313-21.

13. Shore RE. Radiation-induced skin cancer in humans. Med Pediatr Oncol. 2001;36:549-54.

14. Khedr MH, Shafaan MW, Ghaffar AA, Saleh A: Radioprotective efficacy of Ginkgo biloba and Angelica archangelica extract against technetium-99m-sestamibi induced oxidative stress and lens injury in rats. Int J Radiat Biol. 2018:94:37-44.

15. Emerit I, Oganesian N, Sarkisian T, Arutyunyan R, Pogosian A, Asrian, et al. Clastogenic factors in the plasma of Chernobyl accident recovery workers: anticlastogenic effect of Ginkgo biloba extract. Radiat Res. 1995;144:198-205.

16. Morán-Velázquez DC, Monribot-Villanueva JL, Bourdon M, Tang JZ, López-Rosas I, Maceda-López LF, et al. Unravelling chemical composition of agave spines: news from agave fourcroydes Lem. Plants (Basel). 2020;9:1642.

17. Alonso C, Rubio L, Touriño S, Martí M, Barba C, FernándezCampos F, et al. Antioxidative effects and percutaneous absorption of five polyphenols. Free Radic Biol Med. 2014;75:149-55.

Copyright by Lorenzo Martini, et al. This is an open access article distributed under the terms of the Creative Commons Attribution License, which permits unrestricted use, distribution, and reproduction in any medium, provided the original author and source are credited.

Source of Support: Nil, Conflict of Interest: None declared. 